\title{
A FORMAÇÃO DOCENTE E O TECNICISMO PEDAGÓGICO: UM DESAFIO PARA A EDUCAÇÃO CONTEMPORÂNEA
}

\author{
FORMACIÓN DOCENTE Y TECNISCISMO PEDAGÓGICO: UN DESAFÍO \\ PARA LA EDUCACIOÓN CONTEMPORÁNEA
}

\author{
TEACHING EDUCATION AND PEDAGOGICAL TECHNICISM: A \\ CHALLENGE TO THE CONTEMPORARY EDUCATION
}

\author{
Simão ALBERTO ${ }^{1}$ \\ Reginaldo Leandro PLACIDO ${ }^{2}$ \\ Ivonete Telles Medeiros PLACIDO ${ }^{3}$
}

RESUMO: A discussão sobre a formação docente suscita convergências e divergências entre correntes pedagógicas tecnicista e inovadora. Nesse sentido, a temática desafia educadores, especialmente aqueles que atuam na docência do Ensino Superior, a reavaliar a prática docente, pois a aprendizagem pautada em paradigmas conservadores domestifica e imobiliza os sujeitos envolvidos no processo ensino-aprendizagem, tolhendo-lhes sua rebeldia intelectual. Com base nessa premissa, este trabalho aborda a formação docente e a fragmentação do conhecimento, uma herança advinda dos paradigmas conservadores da educação, a partir das abordagens tradicional, escolanovista e tecnicista. Este trabalho oportuniza uma reflexão sobre a prática pedagógica no Ensino Superior na formação docente, e busca provocar uma discussão sobre o professor reflexivo. Além disso, o trabalho aborda o pensamento newtoniano-cartesiano, o tecnicismo, e inserção das tecnologias na educação, no intuito de problematizar as convergências e as divergências entre os paradigmas tecnicista e inovador.

PALAVRAS-CHAVE: Formação docente. Correntes pedagógicas. Tecnologias na educação. Prática docente. Docência no ensino superior.

RESUMEN: La discusión sobre la formación docente plantea convergencias y divergencias entre la pedagogía tecnicista y la innovadora. En este sentido, el tema desafía a los educadores, especialmente a aquellos que trabajan en la enseñanza de educación superior, a reevaluar la práctica educativa, porque el aprendizaje basado en paradigmas conservadores, domestica e inmoviliza a los sujetos involucrados en el proceso de enseñanza-aprendizaje, limitando su rebelión intelectual. Basado en esta premisa, este documento aborda la formación del profesorado y la fragmentación del conocimiento, una herencia de paradigmas conservadores de la educación, basados en los enfoques tradicionales, escolanovistas y

\footnotetext{
${ }^{1}$ Instituto Federal Catarinense (IFC), Araquari - SC - Brasil. Professor EBTT. ORCID: https://orcid.org/00000002-7838-7247. E-mail: simao.alberto@ifc.edu.br

${ }^{2}$ Instituto Federal Catarinense (IFC), Araquari - SC - Brasil. Professor EBTTT, Programa de Pós-Graduação em Educação Profissional e Tecnológica. ORCID: https://orcid.org/0000-0001-5608-2621. E-mail: reginaldo.placido@ifc.edu.br

3 Centro Universitário Leonardo da Vinci (Uniasselvi), Indaial - SC - Brasil. Professora. Faculdades de Educação. ORCID: https://orcid.org/0000-0002-1793-418X. E-mail: ivonete.placido@uniasselvi.com.br
}

RIAEE - Revista Ibero-Americana de Estudos em Educação, Araraquara, v. 15, n. esp. 2, p. 1652-1668, ago. 2020. e-ISSN: $1982-5587$. DOI: https://doi.org/10.21723/riaee.v15iesp2.13837 
tecnicistas. Este artículo proporciona una reflexión sobre la práctica pedagógica en la educación superior en la formación del profesorado, y busca provocar una discusión sobre el profesor reflexivo. Además, el documento aborda el pensamiento newtoniano-cartesiano, el tecnicismo y la inserción de tecnologías en la educación, para problematizar las convergencias y divergencias entre los paradigmas tecnicistas e innovadores.

PALABRAS CLAVE: Formación docente. Corrientes pedagógicas. Tecnologías en la educación. Práctica docente. Enseñanza en la educación superior.

ABSTRACT: The discussion about teacher education generates convergences and divergences between technical and innovative pedagogy. In this sense, the theme challenges educators, especially those working in higher education, to reassess educational practice, because learning based on conservative paradigms domesticates and immobilizes the subjects involved in the teaching-learning process, limiting their intellectual rebellion. Based on this premise, this article addresses teacher education and knowledge fragmentation, a heritage of conservative education paradigms based on traditional, scholastic, and technical approaches. This article provides a reflection on the pedagogical practice in higher education in teacher education and seeks to provoke a discussion about the reflective teacher. In addition, the article addresses Newtonian-Cartesian thinking, technicism and the insertion of technologies in education, in order to problematize the convergences and divergences between the technicist and innovative paradigms.

KEYWORDS: Teacher training. Pedagogical currents. Technologies in education. Teaching practice. University education.

\section{Introdução}

Neste artigo propõe-se discutir a formação docente e o tecnicismo pedagógico tendo como espectro contextual a docência no Ensino Superior. Cabe inicialmente pontuar que esta reflexão tem sua origem em discussões e diálogos trazidos a partir de comunicação realizada no IV Seminário Internacional sobre Profissionalização Docente, onde foram problematizados o tecnicismo pedagógico e o professor reflexivo em contexto amplo da educação. Entretanto, ainda que em boa medida as referências textuais e teóricas daquela comunicação tenham sido mantidas no texto atual, a reflexão foi somada de novos contornos e contribuições que justificam a retomada e ampliação do debate. Neste sentido, buscar-se-á apresentar alguns paradigmas epistemológicos da educação no Brasil, tidos como conservadores, de abordagens tradicional, escolanovista e tecnicista, suas divergências e contribuições para a educação contemporânea, sobretudo na docência no Ensino Superior.

É perceptível que no decorrer dos anos o sistema educacional brasileiro tem passado por várias concepções pedagógicas que, em termos concisos, podem ser entendidas como as diferentes maneiras pelas quais a educação é teorizada e praticada, ou seja, constituindo a 
própria substância da prática educativa. Tais concepções foram, não raras vezes, abraçadas em caráter quase soteriológico, ao invés de metodológico, sobretudo quando motivadas ou guiadas em perspectiva reprodutivista da sociedade e do mundo do trabalho. Sabe-se bem que em uma sociedade globalizada e competitiva, o mundo do trabalho tem como desafio lidar, entre outras coisas, com a competição profissional, já que não existe uma profissão cativa, portanto detentora do mercado de trabalho exclusivo. Ao cingir-se desta reflexão sabe-se que a educação pode contribuir na travessia para uma nova realidade e compreensão deste mundo do trabalho.

A análise da temática proposta permite permear discussões que contribuem para o desafio de uma prática pedagógica que, não apenas corresponda, mas que questione as necessidades de uma sociedade em constantes mudanças. Isso implica afirmar que discutir temas como docência no ensino superior, formação docente e tecnicismo pedagógico proporciona aos sujeitos envolvidos no processo ensino-aprendizagem momentos de profunda reflexão. O professor encontra-se frequentemente com a complexidade do trabalho docente e, diante da deficiência nos processos de formação continuada e das insuficientes oportunidades neste sentido oferecidas pelas instituições de ensino superior, a prática torna-se oportunidade formativa quando possibilita a reflexão crítica da ação realizada, ensejando o planejamento das ações futuras. Apesar da oportunidade de encontrar na reflexão da prática espaço para formação e reflexão crítica, há que se tomar cuidado para não compactuar com a ideia de que a prática por si possa substituir o estudo teórico.

Nestas reflexões ousa-se no presente texto acostar a inserção da discussão sobre o uso de tecnologias na educação para contribuir na travessia e ao mesmo tempo provocar a reflexão sobre os paradigmas newtoniano-cartesiano e sistêmico. Referimo-nos, aqui, ao uso das tecnologias como recursos didáticos que fortalecem a ação pedagógica e não como um fim em si. No que consiste ao uso das tecnologias da educação, a docência no Ensino Superior, especialmente na formação de docentes, não pode se colocar indiferente às mudanças pelas quais o mundo do trabalho enfrenta. Nessa linha de raciocínio, Tescarolo faz um importante alerta a ser considerado:

Não é mais possível negar ou evitar o formidável impacto que as novas tecnologias ligadas ao desenvolvimento das redes informacionais estão produzindo nas atividades humanas, não apenas aquelas ligadas à produção $\mathrm{e}$ ao trabalho, mas também e principalmente à condição de vida do mundo. (TESCAROLO; GASQUE, 2007, p. 43). 
Neste sentido, a formação, além de ser sólida, deve corresponder às necessidades de uma educação que, sobretudo, não menospreza o manuseio das tecnologias educacionais, pois as compreende como um processo criativo através do qual é possível utilizar-se de recursos materiais e imateriais a fim de encontrar respostas para os problemas do seu cotidiano, superando-os. Ou seja, o uso de tais tecnologias desafia o professor a buscar uma formação que o ajude a inovar sua prática docente e que possa contribuir no processo de reflexão do fazer docente.

Em relação ao professor reflexivo, o artigo priorizou a discussão da prática pedagógica, com objetivo de superar a fragmentação do conhecimento científico, pois parte do princípio de que para conhecer as partes é necessário conhecer o todo, para depois conhecer as partes e não ao contrário. Assim, uma atuação docente no Ensino Superior, sólida conceitualmente e coesa em suas práticas, pode possibilitar aos sujeitos do processo ensinoaprendizagem uma formação integral que resulte em cidadania. A reflexão sobre a prática docente no ensino superior torna-se fundamental e necessária para possibilitar uma atuação mais consistente da docência, de maneira que o educador possa desenvolver seu trabalho com êxito, tendo em vista que atuar como professor significa fazer parte de um processo que demanda competência técnica e compromisso ético político. Entretanto, cabe destacar que a reflexão sobre a prática não resolve tudo, a experiência refletida não resolve tudo. Como afirma Libâneo (2005, p. 76), são “necessárias estratégias, procedimentos, modos de fazer, além de uma sólida cultura geral, que ajudam a melhor realizar o trabalho e melhorar a capacidade reflexiva sobre o que e como mudar".

Para poder cerzir formação docente, tecnicismo pedagógico, tecnologia educacional e docente reflexivo, além do diálogo com perspectivas pedagógicas contemporâneas, a argumentação no presente artigo procurou discutir as seguintes indagações: Como a docência no Ensino Superior, na formação docente, pode dialogar com o atual cenário educativo em uma sociedade cujas mudanças são abruptas e inevitáveis? Quais as implicações da abordagem tecnicista à educação em um mundo de trabalho globalizado e competitivo? Que vantagens tem o professor reflexivo ao adotar tecnologias educacionais em sua prática docente para promover uma educação mais justa, ética e humana?

Partindo dessas indagações e com base nas reflexões oriundas das discussões pedagógicas foi possível refletir a temática em diálogo com teóricos da educação. Dessa forma, foi possível provocar uma discussão sobre o professor reflexivo, abordar o pensamento newtoniano-cartesiano, o tecnicismo, a inserção das tecnologias na educação e, por fim, analisar as convergências e as divergências entre os paradigmas tecnicista e inovador. Em 
suma, vale reiterar que a fundamentação teórica do artigo priorizou a análise crítica de especialistas que possuem literatura e estudam a temática, conforme veremos a seguir:

\section{O professor reflexivo e o pensamento newtoniano-cartesiano: uma análise crítica do sistema educacional brasileiro}

No decorrer da pesquisa e levantamento teórico sobre a temática foi possível observar que, na história da educação brasileira, o sistema educacional foi alvo de influências oriundas de diversos paradigmas epistemológicos. A discussão sobre os paradigmas de ensino enriqueceu as reflexões, pois as contribuições advindas do debate são significativas e demonstram que

[...] o paradigma desempenha um papel ao mesmo tempo subterrâneo e soberano em qualquer teoria, doutrina ou ideologia. O paradigma é inconsciente, mas irriga o pensamento consciente, controla-o e, neste sentido, é também supraconsciente (MORIN, 2004, p. 26).

Assim, é possível afirmar que os paradigmas funcionam como regulamentos e regras por meio dos quais o ser humano faz uma leitura da realidade, julgando e classificando os fenômenos e o que "[...] os indivíduos conhecem, pensam e agem segundo paradigmas inscritos culturalmente neles" (MORIN, 2004, p. 25). Analisar a corrente pedagógica à luz do paradigma epistemológico contribui também para compreender o contexto e a construção do pensamento da corrente em si, bem como a influência no sistema educacional e, consequentemente, suas escolhas e práticas pedagógicas.

No caso da pedagogia tecnicista, é necessário situá-la sob a égide da influência do pensamento newtoniano-cartesiano na educação, que parte do princípio de que os fenômenos podem ser compreendidos se forem reduzidos às partes que os constituem. Ou seja, ao conhecer uma parte de um sistema, o pesquisador chegará ao conhecimento de seu funcionamento, diz Capra (1996). Se assim concordarmos, ficaria evidente o pensamento de Vasconcellos (2002), que acredita na supervalorização da mente que originou no paradigma cartesiano dicotomias que resultaram na fragmentação do conhecimento e na concepção linear e mecanicista da história.

Seguindo essa concepção, o ser humano, de fato, torna-se o senhor do mundo, pois acredita em sua capacidade de transformar, explorar, servir-se e escravizar a natureza como afirma Capra (1996). Para Behrens e Oliari (2007, p. 59), o paradigma newtoniano-cartesiano insiste na separação da mente e matéria e fragmentação do conhecimento em diversas partes para buscar maior eficácia. Tal forma de pensamento levou a humanidade a dividir o 
conhecimento em quantas partes conseguisse e foi adquirindo desta forma uma visão fragmentada da realidade que o cercava. Este paradigma trouxe consigo à educação uma herança de fragmentação do conhecimento e a supervalorização da visão racional, e propôs a primazia da razão sobre a emoção, dividindo assim o conhecimento em áreas, cursos e disciplinas, atingindo e reduzindo a prática pedagógica do professor, especialmente no ensino superior, onde a divisão do conhecimento em áreas, às vezes, se sobrepõem ao todo.

Nessas condições, o paradigma newtoniano-cartesiano apresenta-se bem definido enquanto orientador de práticas educativas, cujas ideias e pressuposições são muito bem delineadas; ademais, constitui-se em estruturas mais gerais e determinantes não só da forma de conceber a educação, mas também na maneira de agir educacionalmente. Esta concepção e práticas podem ser observadas, por exemplo, nas estruturas curriculares e nas cátedras que, às vezes, supõem o conhecimento tão fragmentado que torna necessário a exoticidade de ações interdisciplinares, ou seja, reconhecendo a fragmentação do conhecimento na própria arquitetura curricular.

Com base na visão reducionista do conhecimento defendida pelo tecnicismo, o professor reflexivo tem como desafio a formação integral do indivíduo, pois o ser humano é um ente indivisível que "participa da construção do conhecimento não só pelo uso da razão, mas também aliando as emoções, os sentimentos e as intuições” (BEHRENS, 2007, p. 62). Partindo dessa compreensão é possível afirmar que o professor reflexivo é o sujeito capaz de analisar criticamente os contextos históricos, sociais, culturais e organizacionais nos quais ocorrem suas práticas docentes, podendo assim intervir nessa realidade e transformá-la. Portanto cabe a ele transformar o processo ensino-aprendizagem dinâmico, criativo e global. Ademais, trata-se de uma educação sistêmica cuja finalidade é defender a totalidade cósmica, já que o mundo é dinâmico e sua interação se dá em conexão com outros elementos determinados pela dinâmica do todo.

Nesse aspecto, não seria pertinente que as partes que compõem o mundo fossem compreendidas como entidades isoladas. A visão fragmentada ocasionada pelo paradigma newtoniano cartesiano levou à reprodução do conhecimento, e quanto mais o estudante chega ao ensino superior de ensino mais esta fragmentação é percebida. Assim sendo, o professor tem o dever de proporcionar ao educando um sistema educativo que priorize o resgate do indivíduo na sua totalidade. Assim, na atual conjuntura faz-se jus ao sistema de ensino que seja compatível com a nova leitura de mundo advindo da visão sistêmica e complexa do universo. Ou seja, uma educação que recupere o "equilíbrio entre a intuição e a razão, propondo um ensino e uma aprendizagem que levem à produção de conhecimento autônomo, 
crítico e reflexivo e à construção de uma sociedade mais justa, igualitária, fraterna e solidária" (BEHRENS, 2007, p. 65). Para isso, é necessária uma educação pautada na reflexão crítica e criativa. Dessa forma, a "reflexão e educação são temas indissolúveis ou, pelo menos, deveriam ser, isto é, a escola deve ser, necessária e essencialmente, o lugar geográfíco da construção e do diálogo crítico" (GHEDIN, 2002, p. 146). O professor reflexivo deve envidar esforços para que os seus alunos busquem um aprendizado que se fundamente na reflexão crítica, embora o processo da reflexão exija tempo. Aliás, Ghedin acrescentou:

O processo reflexivo não surge por acaso. Ele é resultado de uma longa trajetória de formação que se estende pela vida, pois é uma maneira de se compreender a própria vida em seu processo. Não é algo impossível de realizar-se. É difícil porque a sociedade em que nos encontramos, de modo geral, não propicia espaços para a existência da reflexão e da educação, em particular não raro reduz-se à transmissão de conteúdos mais do que à reflexão sobre eles e suas causas geradoras (GHEDIN, 2002, p. 147).

Diante do exposto, a educação que nos referimos é aquela que considera tanto educador como educando sujeitos na ação educativa, pois estão em constante interação e mediação do processo ensino-aprendizagem. Vale ressaltar que o processo de interação e mediação só é possível mediante uma prática educativa dialógica por parte dos educadores, se estes acreditam no diálogo como um fenômeno humano capaz de mobilizar o refletir e o agir dos homens e mulheres. Assim, requer-se uma prática de ensino que difere da educação bancária, pois "anula o poder criador dos educandos ou o minimiza, estimulando sua ingenuidade e não a criatividade, satisfaz aos interesses dos opressores: para esses, o fundamental não é o desnudamento do mundo, a sua transformação" (FREIRE, 2005, p. 69).

Ao fragmentar o conhecimento, o pensamento newtoniano-cartesiano tende a alimentar o paternalismo no sistema de ensino, pelo fato de que os oprimidos recebem o nome de simpáticos e 'assistidos' (FREIRE, 2005). É dever do professor enquanto educador ousar e promover mudanças na busca do novo. Caso contrário, o sistema educacional corre risco de entrar em colapso, pois estaria repetindo mesmos erros advindos da educação bancária. Em busca de uma educação libertadora, é prudente que o professor tenha "a coragem de romper consigo mesmo para poder instaurar uma nova compreensão da ação e dela imprimir uma nova ação reflexiva, tornando possível a ampliação do poder de autodeterminação" (GHEDIN, 2002, p. 148). Somente com a coragem e a determinação será possível pensar na construção de cidadania responsável capaz de promover a democracia participativa.

Além do mais, torna-se importante que a educação contemporânea propicie aos sujeitos do processo ensino-aprendizagem espaços de reflexão crítica e criativa, como 
condição necessária à socialização, à humanização, permeando assim um novo horizonte de compreensão do sentido da existência humana e de todas as coisas diante de novas perspectivas, adverte Ghedin (2002, p. 149).

Referindo-nos ainda ao paradigma newtoniano-cartesiano, é importante admitir sua crise com o pensamento sistêmico. Podemos, inclusive, citar a crise de relação com as tecnologias na educação. De um lado não se pode negar que a tecnologia da informação facilitou a comunicação, bem como encurtou distâncias entre os sujeitos envolvidos no processo educacional. Apesar disso, a facilidade de lidar com tecnologias da informação tem causado sérios problemas para essa sociedade em processo de globalização, pois encurtar distâncias nem sempre é sinônimo de aproximação e solidariedade entre as pessoas, como bem nos lembra Behrens:

[...] os avanços técnicos, científicos e eletrônicos não trouxeram a vida em plenitude para os homens. Ao contrário vieram desafiá-los e angústia-los, levando ao estresse, à competitividade exacerbada, a um pensamento isolado e fragmentado, impedindo de ver o todo e retirando responsabilidade dos atos isolados dos homens perante a sociedade (BEHRENS, 2005, p. 28).

Seguindo a linha de raciocínio da Behrens, não é possível olhar em separado os problemas globais tentando entendê-los e resolvê-los. Pautados em uma compreensão global do mundo é possível afirmar que o paradigma newtoniano-cartesiano está em crise, pois o mundo passou a ser influenciado pelo pensamento sistêmico, defendendo o estudo das partes a partir do todo. Aliás, a visão sistêmica é contrária à fragmentação do conhecimento, conforme propunha o pensamento newtoniano-cartesiano. A despeito, é importante que o professor em sua prática docente priorize a mudança de paradigmas, a fim de transformar o fazer pedagógico.

Todavia, vale lembrar que nenhuma mudança acontece de maneira abrupta, movida por ameaças, rupturas ou imposição. Mudar com sucesso exige conquista, compromisso e envolvimentos dos sujeitos. Por esta razão o professor reflexivo não pode ignorar, em hipótese alguma, a revolução tecnológica que sutilmente invade o mundo. Pelo contrário, o professor deve entender que tecnologias educacionais são recursos pedagógicos em potenciais, cujo propósito é auxiliar o docente em sua prática docente. Assim, cabe ao professor um olhar atento e cuidadoso para não cair no engodo da perspectiva soteriológica das tecnologias, pois as mesmas não substituem o fazer docente.

As tecnologias de ensino vieram para ficar. Portanto, ignorá-las seria o mesmo que fechar os olhos a um caminho sem volta, pois a todo instante imerge sua necessidade. Há que 
compreender que existe uma perspectiva de globalização que vêm forçando os países a investir na tecnologia, independentemente de suas possibilidades econômicas e do respeito necessário à categoria docente.

\section{As tecnologias educacionais, sua inserção na educação brasileira e os efeitos da pedagogia tecnicista}

Sampaio e Leite (2008) afirmam que as discussões mais sistematizadas sobre tecnologias de educação no Brasil iniciaram a partir da década de 60 , e sua utilização era baseada na teoria pedagógica tecnicista que empregava recursos técnicos na educação sem questionar sua utilidade para aprimorar o desempenho do professor.

Em seu livro Escola e Democracia, Dermeval Saviani (1985) faz uma análise crítica descrevendo a pedagogia tecnicista, ao lado da pedagogia tradicional e da pedagogia nova, como teoria não crítica, pois sua crença reside na ideia de que a educação é a panaceia milagrosa capaz de erradicar a marginalidade de nossa sociedade. Saviani é de opinião que na pedagogia tradicional o marginalizado é o ignorante e na pedagogia nova, o rejeitado, enquanto na pedagogia tecnicista o marginalizado é o incompetente tecnicamente, o ineficiente e improdutivo. Nessa abordagem pedagógica, a educação exerce um importante papel, porque busca superar o problema da marginalidade na medida em que formar indivíduos capazes de contribuir para o aumento da produtividade da sociedade. Para Behrens (2005), o conjunto de teorias não críticas está inserido dentro do que é designado de paradigma conservador, caracterizando-o pela reprodução do conhecimento a partir da repetição e da memorização.

Ora, a pedagogia tecnicista tem sua concepção de ensino pautada no behaviorismo, também conhecido por comportamentalismo, uma corrente psicológica propugnada por Skinner, e na abordagem sistêmica de ensino, que traz como verdade absoluta a neutralidade científica. Mas o tecnicismo no Brasil surge a partir da década de 60 (1964), devido aos "baixos índices da satisfação da demanda escolar em relação ao total da produção e pelos altos índices de evasão e repetência" (KUENZER, 1982, p. 29). No campo da educação o comportamentalismo teve como principal característica o controle rígido das atividades pedagógicas, dirigidas de forma mecânica, automática, repetitiva e programada. Aliado a interesses políticos e econômicos, o tecnicismo centra os esforços no planejamento e controle do método de produção. Kuenzer afirma: 
Esta teoria surge tendo como preocupação central o controle do processo produtivo, necessidade gerada pelo desenvolvimento capitalista que, introduzindo novas relações de produção a partir da compra e venda de força de trabalho, transfere o controle realizado internamente pelo produtor, a uma instância superior a ele: a da gerência (KUENZER, 1982, p. 31).

Segundo o pensamento behaviorista de ensino o Estado está a serviço do capital, pois, de forma intervencionista, por meio da educação, ele consegue interferir no mercado de trabalho a ponto de o próprio Estado tornar-se também capitalista, gerindo empresas lucrativas e priorizando a eficiência na produção. A esse respeito, Frigotto completa:

O Estado intervencionista, em suma, vai-se caracterizar como o patamar por onde passam os interesses intercapitalistas, e cumpre a um tempo e de modo inter-relacionado: uma função econômica, enquanto cada vez mais se torna ele mesmo produtor de mais valia ou garantindo, por diferentes mecanismos (subsídios, absorção de perdas) ao grande capital privado esta produção; uma função política enquanto intervém politicamente para gerar as condições favoráveis ao lucro; e uma função ideológica enquanto se apresenta como um mediador do bem comum, uma força acima de qualquer suspeita e acima do antagonismo de classes (FRIGOTTO, 2001, p. 119).

Em busca da neutralidade científica, a pedagogia tecnicista planeja "a educação de modo a dotá-la de uma organização racional capaz de minimizar as interferências subjetivas que pudessem pôr em risco sua eficiência" (SAVIANI, 2003, p. 12). A partir do pressuposto desta dita neutralidade científica e inspirada nos princípios de racionalidade, eficiência e produtividade, a pedagogia tecnicista advoga a reordenação do processo educativo de maneira a torná-lo objetivo e operacional. Nesse aspecto, a educação torna-se um movimento fechado em si mesmo, sem qualquer tipo de interação com o seu entorno envolvente ou com questões sociais e, portanto, sem a capacidade de diálogo e de ser propositiva das transformações humanas. Daí a proliferação de propostas pedagógicas tais como o enfoque sistêmico, o microensino, o telensino, a instrução programada, as máquinas de ensinar.

Na pedagogia tecnicista, o elemento principal passa a ser a organização racional dos meios, ocupando o professor e o aluno posição secundária, relegados que são à condição de executores de um processo cuja concepção, planejamento, coordenação e controle ficam a cargo de especialistas supostamente habilitados, neutros, objetivos, imparciais. Ao que parece esta postura contraria o entendimento de que a "educação é a comunicação entre pessoas livres em graus diferentes de maturação humana, é a promoção do homem, de parte a parte, isto é, tanto do educando como do educador" (SAVIANI; DUARTE, 2010, p. 423).

A inserção das tecnologias no campo da educação, na pedagogia tecnicista, é uma realidade irreversível. Aliás, nesta perspectiva as modernas tecnologias se destinam, portanto, 
à resolução de problemas internos, surgidos dentro de um âmbito reduzido. Nessas condições, o tecnicismo acabou por contribuir para aumentar o caos no campo educativo, gerando tal nível de descontinuidade, de heterogeneidade e de fragmentação que praticamente inviabilizou o trabalho pedagógico. Saviani (2003, p. 15) vai mais além, ao afirmar que "na prática educativa, a orientação tecnicista cruzou com as condições tradicionais predominantes nas escolas, bem como com a influência da pedagogia nova que exerceu poderoso atrativo sobre os educadores". É perceptível que exista no tecnicismo uma forte influência positivista que provoca cisão entre sujeito e objeto, fazendo com que a educação se torne fragmentada e mecanicista. Pensando como Saviani, diríamos que no tecnicismo a ênfase da prática educativa recai na técnica pela técnica, pois busca em manuais instruções sobre como organizar o processo de ensino.

Skinner, o pesquisador que influenciou o tecnicismo, sensível a transformações do seu tempo, utilizou o termo Tecnologia do Ensino para denominar um campo que nasceu de seus estudos do comportamento humano do qual, segundo ele, seria possível deduzir programas, esquemas e métodos de instrução. De fato, a partir de sua linha de pensamento foram criadas tecnologias para o ensino, no intuito de alcançar resultados. É óbvio que a perspectiva de tecnologia educacional permitiu o surgimento de novas técnicas de dominação do capital e na inoculação de uma cultura de disciplina fabril.

Entretanto, no meio educacional o preconceito talvez tenha também sua origem no sistema de ensino vivenciado pela escola brasileira na década de 60, já que, nesse período, toda tentativa de levar para a sala novo equipamento tecnológico produzido pela sociedade industrial era associada a um projeto político e econômico, cujos objetivos visavam inserir o Brasil no mercado mundial como produtor e consumidor de bens. Isso, na educação, se traduziu na defesa de um modelo tecnicista, preconizando o uso das tecnologias como fator de modernização da prática pedagógica e solução de todos os seus problemas (LEITE; POCHO; AGUIAR; SAMPAIO, 2003).

Sá-Filho e Machado (2003, p. 4) afirmam que este modelo é "falacioso, pois a relevância pedagógica da inserção da tecnologia educacional no processo pedagógico será determinada pelo uso adequado que dela se faz". Isto, talvez, porque a pedagogia tecnicista cuja prática pedagógica se baseia na reprodução do conhecimento, nas aulas expositivas e nos exercícios repetitivos, faz com que as tecnologias educacionais se tornem mecanismos em potencial para facilitar a reprodução fiel do conteúdo, bem como assimilação e repetição do mesmo, não obstante para a pedagogia tecnicista o que importa é aprender a fazer, observa Saviani (2003). Aliás, nessa concepção pedagógica o centro do processo ensino-aprendizagem 
não está no professor e no aluno, mas nos próprios meios aplicados como recursos didáticos pedagógicos, sem questionar suas finalidades. Afirma Saviani:

Na pedagogia tecnicista, o elemento principal passa a ser a organização, racional dos meios, ocupando o professor e o aluno posição secundária, relegados que são à condição de executores de um processo cuja concepção, planejamento, coordenação e controle ficam a cargo de especialistas supostamente habilitados, neutros, objetivos, imparciais (SAVIANI, 2003, p. $13)$.

É evidente que na pedagogia tecnicista o elemento principal passa a ser a organização racional dos meios, enquanto isso o professor e o aluno ocupam a posição secundária, isto é, assumindo a condição de executores de um processo cuja concepção, planejamento, coordenação e controle ficam a cargo de especialistas supostamente habilitados, neutros, objetivos, imparciais (SAVIANI, 2003). Nesse sentido, o tecnicismo deturpa o real significado pelo uso das tecnologias educacionais na escola. No tecnicismo a função do aluno consiste em aprender a fazer. Eis aí uma das razões por que devemos indagar: O que pode ser feito para que as tecnologias educacionais não se transformem num problema social contrário à dignidade humana? Ignorar sua inserção no sistema educacional é o ideal? O que fazer, então, para que o atual sistema educacional não repita os erros cometidos pela educação bancária, mas fazer das tecnologias educacionais ferramentas pedagógicas que possam auxiliar o professor em sua prática docente? Respondendo as questões diríamos que só é possível com base na análise crítica das convergências e divergências oriundas do confronto pedagógico entre o tecnicismo e o paradigma inovador do ensino, como veremos a seguir.

Apesar da perspectiva e conceito que se possa construir de tecnologias educacionais a partir da perspectiva tecnicista, é necessário romper com o paradigma e com o conceito em si. Desta forma, no tocante às tecnologias educacionais, vale esclarecer que o significado de tecnologia é elástico e, portanto, capaz de ganhar diferentes conotações. De fato, o termo tecnologia possui um significado abrangente que envolve desde os processos e ferramentas mais simples até os mais complexos desenvolvidos pela humanidade. Leite, Pocho, Aguiar e Sampaio (2003, p. 11) nos ajudam a ampliar nossa visão e pensar didaticamente, por afirmar que as tecnologias educacionais podem ser agrupadas em dois grupos: as tecnologias da informação e da comunicação: a televisão, o vídeo, o computador, o rádio, a filmadora, a máquina fotográfica, etc.; aquelas não informatizadas ou dependentes de recursos elétricos ou eletrônicos: quadro-de-giz, quadro-de-pregas, histórias em quadrinhos, o jornal, a sucata, o livro, o caderno, a caneta, etc.; vale dizer que inserir as tecnologias educacionais no atual 
sistema de ensino pode favorecer a prática pedagógica inovadora. $\mathrm{O}$ uso destas tecnologias não pode ser confundido com o sentido de tecnologias educacionais da concepção tecnicista.

Diante do exposto, ignorar a inserção de tecnologias educacionais na educação contemporânea constitui um retrocesso desastroso. Aliás, ignorar a presença de tecnologias da educação seria o mesmo que admitir o retrocesso científico e educacional. Quanto à inserção das tecnologias educacionais na escola, talvez ainda exista algum preconceito por parte de alguns professores que receiam mudar seus paradigmas. $\mathrm{Na}$ atual conjuntura educacional, não há a menor possibilidade de evitar o uso das tecnologias no sistema educacional. Assim, cabe aos professores superar o medo e a desconfiança e inserir o uso das tecnologias como recursos pedagógicos em sua prática docente.

\section{O paradigma inovador e o tecnicismo: convergências e divergências na prática docente do professor}

Durante o desenvolvimento da pesquisa, foi possível detectar algumas convergências e divergências nas duas abordagens (a tecnicista e a inovadora). As convergências consistem no fato de ambas as abordagens fazerem o uso das tecnologias. Embora divirjam quanto à importância na sua aplicação, a primeira faz das tecnologias educacionais, recursos didáticos pedagógicos que auxiliam o professor em sua atividade profissional, enquanto que a segunda entende que o domínio das tecnologias seja a condição para a formação profisssional.

Em relação às divergências, elas residem no fato de o paradigma inovador defender a formação integral do ser-aluno, ou seja, ele é contra o reducionismo cartesiano, cuja tendência é fragmentar o conhecimento. No paradigma inovador o professor e o aluno são sujeitos do processo ensino-aprendizagem, pois ambos têm por objetivo construir o conhecimento. Em contrapartida na pedagogia tecnicista o conhecimento acontece de forma fragmentada e em partes isoladas, isto é, a compreensão do todo depende da compreensão das partes. Procedendo assim, a pedagogia tecnicista deixa muito a desejar, mesmo porque tudo está interligado entre si. Para Cardoso (1995, p. 36), existe "interdependência entre os vários planos de totalidade [...] pessoal, comunitária, social, planetário e cósmico. Tudo o que ocorre em um dos planos repercute nos demais".

No que tange ao avanço científico e tecnológico e às constantes transformações das quais o sistema educacional brasileiro enfrenta, devem ser entendidos como sendo um caminho sem volta. Isso implica afirmar que a inserção de tecnologias no campo educacional além de necessárias são inevitáveis. Diante da realidade inegável, o professor deve repensar a 
sua prática pedagógica, pois a educação contemporânea não tolera improvisos. O momento atual instiga os sujeitos do processo ensino-aprendizagem a descortinar o cenário da educação, contextualizá-lo e transformá-lo num processo social mais amplo, transformando-o em gênese e consolidação do movimento emergente de uma nova sociedade entendida por Castells (1999) como a sociedade do conhecimento.

Mais do que correr atrás de informações e conhecimento, a complexidade das exigências impostas pelo mundo de trabalho competitivo exige do professor uma preparação coesa e segura, que lhe permita compreender o significado das coisas partindo da compreensão do todo e não das partes isoladas. Eis aí uma questão aparentemente simples, mas de extremo valor para a construção do conhecimento. É valiosa porque procura situar o conhecimento ultrapassando a aparente objetividade das informações. Trata-se, portanto, de uma questão epistemológica: mais do que conhecer, implica pensar o conhecimento.

Com o advento das tecnologias na educação, isto é, a partir da década de 1980, o pensamento mais crítico assume os debates pedagógicos, exigindo a contextualização da educação com as questões sociais e suas contradições, buscando o desenvolvimento integral dos sujeitos pensantes e sua inserção crítica no mundo. Não basta utilizar a tecnologia, mas é preciso inovar a prática pedagógica, o grande desafio para que a escola construa um projeto pedagógico que permita a formação de cidadãos plenos. As tecnologias estarão inseridas nesse projeto como forma de proporcionar aos professores e aos alunos uma profunda relação com o conhecimento, isto porque ao trabalhar com as tecnologias, de forma crítica, o professor cria condições para que os alunos consigam lidar com as tecnologias da sociedade, apropriando-se delas como sujeitos (LEITE, 2003).

Assim, inserir as tecnologias educacionais no processo pedagógico a partir de um paradigma inovador desperta o professor para inovar sua prática docente, mantendo o equilíbrio no emprego das tecnologias. Estamos falando da utilização das tecnologias como material didático de forma crítica e reflexiva. Nessas condições, o paradigma educacional instiga o professor a buscar inovações na ação pedagógica, no sentido de propor metodologias que levem à produção do conhecimento, superando a mera reprodução e, consequentemente, formar profissionais que venham a atuar como cidadãos críticos e criativos. Dessa forma, o paradigma inovador de ensino aposta na fusão de estilos de aprendizagem, na pluralidade de métodos, na diversidade de atividades que fomentem a reflexão, nos ambientes pedagógicos que favoreçam a interação entre os participantes do processo ensino-aprendizagem.

Em suma, na atual conjuntura, deve-se admitir que o uso das tecnologias educacionais na prática pedagógica não pode ser entendido como um fim em si. Pelo contrário, usá-las 
como recursos didáticos que auxiliem o professor no seu labor pedagógico. O perigo reside quando tais tecnologias são transformadas em fim em si, acentuando o reducionismo cartesiano centrado na racionalidade, deixando de lado as emoções, ou seja, tornando o homem um ser divisível. O professor ao adotar as tecnologias educacionais como recursos pedagógicos transforma a sua prática pedagógica no aprender a aprender, porque o uso das tecnologias se transforma em um desafio que instiga o professor à atualização constante.

\section{Considerações finais}

A elaboração deste artigo causou-nos um certo desconforto, pois vimo-nos diante de uma provocação profissional. Fomos emulados a repensar nossa prática pedagógica docente em um mundo de constantes e abruptas mudanças. A discussão sobre a temática impactounos, pois instigou-nos a rever nossos paradigmas de ensino. Em cada etapa de sua elaboração, víamo-nos forjados a despir da velha roupagem pedagógica, herança advinda da educação bancária, uma educação que por muitos anos tolheu nossa liberdade e rebeldia intelectual, reduzindo-nos a meros depositários de informações dos professores. Ao tolher-nos a liberdade criativa, esse sistema educacional de ensino fragmentou o nosso conhecimento.

Outrossim, a elaboração da pesquisa dirimiu nossas dúvidas, bem como facilitou o entendimento no que tange à inserção das tecnologias na educação contemporânea, pois sua presença na educação é um processo praticamente irreversível. Diante disso, o professor deve envidar o esforço para conhecê-las e inseri-las em sua prática docente como potenciais recursos pedagógicos do processo de ensino.

Feita a análise pode-se afirmar que, na atual conjuntura educacional, mudar de paradigmas é possível e é necessário, desde que feito com critérios, permitindo aos sujeitos envolvidos (educadores e educandos) compromisso e participação. Todavia, vale ressaltar que mudanças abruptas não são recomendadas. Exige-se mudanças coesas e seguras e elas só podem acontecer de maneira consciente e sem precipitações movidas por ameaças ou irresponsabilidade profissional.

São necessárias mudanças responsáveis que instiguem o professor a despir-se dos paradigmas conservadores do ensino, cuja ênfase está na fragmentação do conhecimento, em busca de uma prática docente pedagógica que contemple a formação integral do homem. Finalmente, a discussão sobre a temática não se esgota neste estudo, mas os elementos aqui analisados dão aos futuros pesquisadores subsídios para prosseguirem os estudos, permitindo a academia material para novos debates. 


\section{REFERÊNCIAS}

BEHRENS, M.; OLIARI, A. A evolução dos paradigmas na educação: do pensamento científico tradicional à complexidade. Revista Diálogo Educacional, Curitiba, v. 7, n. 22, p. 53-66, set./dez. 2007.

BEHRENS, M.; OLIARI, A. O paradigma emergente e a prática pedagógica. Petrópolis, Rio de Janeiro: Vozes, 2005.

CAPRA, F. A teia da vida: uma nova compreensão científica dos sistemas vivos. São Paulo: Cultrix, 1996.

CARDOSO, C. A canção da inteireza: uma visão holística da educação. São Paulo: Sammus, 1995.

DEWEY, J. Democracia e educação: introdução à filosofia da educação. São Paulo: Companhia Editora Nacional, 1959.

FREIRE, P. Pedagogia do oprimido. Rio de Janeiro: Paz e Terra, 2005.

GHEDIN, E. Professor reflexivo: da alienação da técnica à autonomia crítica. In: Professor reflexivo no Brasil. São Paulo: Cortez, 2002.

LEITE, L. et al. Tecnologia educacional: descubra suas possibilidades na sala de aula. Petrópolis, Rio de Janeiro: Vozes, 2003.

MORIN, E. Os sete saberes necessários à educação do futuro. São Paulo: Cortez, 2004.

KUENZER, A. Z.; MACHADO, L. R. de S. A pedagogia tecnicista. In: MELLO, G. N. (Org.). Escola, tecnicismo e educação compensatória. São Paulo: Loyola, 1982.

OLIVEIRA, C. Ambientes informatizados de aprendizagem: produção e avaliação de software educativo. Campinas: Papirus, 2001.

PERRENOUD, P. Práticas Pedagógicas, Profissão docente e Formação. Perspectivas Sociológicas. Lisboa: Publicações. 1993.

SÁ-FILHO, C.; MACHADO, E. de C. O computador como agente transformador da educação e o papel do objeto de aprendizagem. Disponível em:

http://www.abed.org.br/seminario2003/texto11.htm. Acesso em: 28 jun 2019.

SAMPAIO, M. N., LEITE, L. S. Alfabetização tecnológica do professor. Petropólis: Vozes, 2008.

SAVIANI, D. Escola e democracia. Campinas: Autores Associados Cortez, 2003.

SAVIANI, D., DUARTE, N. A formação humana na perspectiva histórico-ontológica.

Revista Brasileira de Educação, Rio de Janeiro, v. 15, n. 45, p. 422-433, set./dez. 2010. 
TESCAROLO, R.; GASQUE, K. C. G. D. Complexidade, currículo e ética: o parto de um novo mundo. Revista Diálogo Educacional, Curitiba, v. 7, n. 22, p. 39-52, set./dez. 2007.

VASCONCELLOS, M. Pensamento sistêmico: novo paradigma da ciência. Campinas:

Papirus, 2002.

\section{Como referenciar este artigo}

ALBERTO, S.; PLACIDO, R. L.; PLACIDO, I. T. M. Docência nos cursos de formação de professores que ensinam matemática: o que as pesquisas revelam? Revista Ibero-Americana de Estudos em Educação, Araraquara, v. 15, n. esp. 2, p. 1652-1668, ago. 2020. e-ISSN: 1982-5587. DOI: https://doi.org/10.21723/riaee.v15iesp2.13837

Submetido em: 30/08/2019

Revisões requeridas: $30 / 11 / 2019$

Aprovado em: 02/02/2020

Publicado em: 01/08/2020 